\title{
Psychotherapy services and the NHS
}

\author{
Raymond Haddock
}

Psychotherapy is an effective treatment (Holmes, 1994: Parry \& Richardson, 1996; Roth \& Fonagy, 1996) and has been recognised as a subspeciality within psychiatry for over 20 years. Training in a range of models is now considered essential for trainee psychiatrists (Royal College of Psychiatrists, 1993).

The review of strategic policy of the National Health Service (NHS) Psychotherapy Services in England (Parry \& Richardson, 1996) is, to date, the most comprehensive and supportive of psychotherapy services in England (Garelick, 1998: Temple, 1998). It reports that in many instances psychotherapy services are poorly organised and coordinated. It recommends that services provide a range of modalities in a coordinated, user-friendly, safe, clinically and costeffective way. They should integrate research, audit, education and experience to develop guidelines, protocols and the practice of psychotherapy.

There are reports of well-organised services using both single and multiple therapeutic modalities to provide a resource for clinical work. consultation and supervision (Whyte, 1989; Holmes \& Mitchison, 1995). These are usually centred in teaching districts, providing services city-wide or at regional level. But even these often do not provide a full range of services and have long waiting times for treatment (Parry \& Richardson, 1996). There is little evidence, however, of widespread organisation of services along the lines recommended in the review.

Services to smaller populations away from teaching centres are often patchy and are provided on a part-time basis with little support or development for therapists. Such services are vulnerable to local changes in political climate, personnel and conflicts over limited resources.

Specific staffing issues have been considered Whyte, 1989; Grant et al, 1991; Psychotherapy Specialist Section of Royal College of Psychiatrists, 1992) but there is little evidence suggesting the resources required to provide comprehensive psychotherapy to a given population. Garelick (1998) did, however, estimate that for one London Health Authority spending on psychoanalytical psychotherapy was $1 \%$ of the mental health budget, and 27 pence per annum was spent on individual psychotherapy. In Sheffield, specialist psychoanalytical and cognitive-behavioural services account for approximately $2 \%$ of the adult mental health budget, with the cost per head of individual psychoanalytical psychotherapy being approximately 16 pence.

There is, therefore, a pressing need for agreement on appropriate resource levels for effective psychotherapy services.

\section{The White Paper The NHS - Modern, Dependable}

The Government White Paper (NHS Executive, 1997) reinforces the move of the previous government to a primary-care-driven and delivered health service with an explicit framework and commitment towards equitable access to high-quality, effective, accountable services (NHS Executive, 1998a).

The Green Paper Our Healthier Nation (Department of Health, 1998) focuses on health promotion and improvement, with key targets in heart disease and stroke, accidents, cancer and mental health (specifically reducing suicides). New and existing resources therefore will be directed towards these target areas and psychotherapy must be in a position to make a key contribution to the nation's health.

Other consultation documents propose changes that will have an impact on future decisions about psychotherapy services:

(a) Draft Guidance on Out of Area Treatment proposes replacement of extra contractual referrals with service agreements with Primary Care Groups (NHS Executive. 1998c).

(b) Consultation on Commissioning Specialised Services clarifies that specialised services will fall within the frameworks set out in the White and Green Papers (NHS Executive, 1998b).

(c) Annex $\mathrm{C}$ of the above document lists selection criteria for specialised services. Psychotherapy services, although not 
specifically mentioned, would fall within the criteria.

These changes are likely to have a significant impact on psychotherapy services by changing the way in which they are funded, commissioned and organised.

\section{Options for psychotherapy services in the 'New NHS'}

An effective psychotherapy service is accessible to all patients and other professionals and is accountable for the effectiveness and quality of the services provided. The challenge is to use the opportunity of the NHS changes to achieve this goal, particularly for small services.

The options are to organise psychotherapy:

(a) as part of primary care groups;

(b) as city-wide services, purchased by a single health authority:

(c) as specialised regional or sub-regional services, commissioned by a number of health authorities or a region.

\section{Views of psychotherapy service stafi}

The Specialist Psychotherapy Directorate of Community Health. Sheffield provides a range of specialist services, including psychoanalytical and group analytical psychotherapy, cognitivebehavioural therapy, relationship and sexual dysfunction and eating disorders, to Sheffield and increasingly to the surrounding districts. The staff met for a facilitated half-day to consider the implications of each option. The aim was to consider the views and opinions of all staff and reach a directorate consensus on the most effective organisation of services to achieve the new agenda for health. Information was provided covering the main aspects of the White Paper (NHS Executive, 1997), the Green Paper (Department of Health, 1998) and the strategic review of NHS psychotherapy services (Parry \& Richardson, 1996).

The strengths, weaknesses, opportunities and threats (SWOT analysis) were considered for each option, in order to provide a framework within which key issues could be identified and debated (see Table 1).

\section{Discussion}

It was agreed that, fundamental to any service changes, the ability of the therapist to work as a specialist should be maintained and developed. also, services should be available to the whole population on an equitable basis. The following discussion will focus on key issues identified by staff that may contribute to the success or failure of a small specialist service.
Becoming marginalised, isolated or losing identity, if working as an individual in a large service, was a concern. A number of staff had experience of working in community mental health teams and found that this eroded their ability to utilise their specialist skills due to pressure to be 'another pair of hands'. They also had little or no access to support and supervision from other specialist therapists. There was a lack of personal and professional development, with their contribution to training, research and service development compromised. This contributed to staff feeling demoralised and losing motivation.

Another issue is related to centralised services being perceived by others as distant, elitist or irrelevant with no direct accountability to local service users. However, the experience of working in specialist teams was positive and had already proved productive. There were opportunities for the development of services, audit, research and personal development and supervision, with an ability to recruit to posts at a time when other services had difficulty filling theirs. In view of these advantages it was felt important to preserve the team structure, which enables specialist teams to collaborate. The structure also provides individuals with a sense of identity and a framework for professional accountability.

If the resources were devolved to primary care groups serving a population of around 100000 . then this would enable local accountability. However, it is unlikely that there would be sufficient therapists to enable staff to perform the functions of a specialist service as outlined above. Our services were already being provided on a city-wide basis with increasing sub-regional activity. This was proving successful in the development of teamwork and new services. Staff were aware, however, that the thrust of the changes was towards locally relevant, responsive services delivered close to people's homes. As the discussion progressed, staff realised that the benefits of being organised as a specialised unit and working closely with users in primary and secondary care could be attained.

\section{Conclusion}

The exercise was successful in reaching a consensus on a positive way forward for the directorate that would preserve the strengths of our specialist skills and identity. It was agreed that the team structure should continue to develop, with particular attention paid to relationships, communication and service agreements with all the users or potential users of our services. For this directorate, consolidating our position as a city-wide provider to a number of primary care groups and further developing 
Table 1. Strengths, weaknesses, opportunities and threats (SWOT analysis) of three options for organising psychotherapy services

\begin{tabular}{|c|c|c|c|}
\hline & Primary Care Groups & Clty-wide & Sub-regional \\
\hline$S$ & $\begin{array}{l}\text { Local service; easy access; } \\
\text { user friendly } \\
\text { Better liaison/influence with } \\
\text { health professionals } \\
\text { Integrated service; early } \\
\text { intervention } \\
\text { Health promoting: locally } \\
\text { appropriate } \\
\text { GP 'Ownership' } \\
\text { Low 'Did not attend' rates }\end{array}$ & $\begin{array}{l}\text { Consistent funding. } \\
\text { Unks with GPs strong } \\
\text { Focused effort - less } \\
\text { 'marketing' effort } \\
\text { Collaboration with mental } \\
\text { health services better } \\
\text { Potential for other services } \\
\text { being developed } \\
\text { Predictable }\end{array}$ & $\begin{array}{l}\text { Better therapy for patients } \\
\text { Staff support } \\
\text { Economy of scale } \\
\text { Large need/profile/critical mass } \\
\text { Quality standards/equitable } \\
\text { availability } \\
\text { Opportunities for research and } \\
\text { specialisation and innovation } \\
\text { More comprehensive service } \\
\text { (in-patient beds?) } \\
\text { Teaching/training - pool of staff }\end{array}$ \\
\hline W & $\begin{array}{l}\text { Small numbers of referrals - } \\
\text { generic work } \\
\text { Loss of skills } \\
\text { Inefficient use of time } \\
\text { Professional isolation } \\
\text { Inefficient specialist } \\
\text { interests } \\
\text { Teaching/training reduced } \\
\text { GP lack of knowledge/ } \\
\text { power in purchasing } \\
\text { Reduced availability of } \\
\text { services }\end{array}$ & $\begin{array}{l}\text { Complacency; lack of } \\
\text { critical mass } \\
\text { Limited opportunities for } \\
\text { development } \\
\text { Restricted research/teaching } \\
\text { opportunities } \\
\text { Less availability of skills (less } \\
\text { staff) } \\
\text { Therapy availability reduced } \\
\text { regionally } \\
\text { Reduced range of services }\end{array}$ & $\begin{array}{l}\text { Centralisation/access/ellism } \\
\text { Separation/loss of partnership } \\
\text { with mental health service } \\
\text { Weaker links with GPs } \\
\text { Perceived loss of 'Sheffield' } \\
\text { service } \\
\text { Lack of similar initiatives } \\
\text { elsewhere }\end{array}$ \\
\hline O & $\begin{array}{l}\text { Increase in influence on } \\
\text { primary care } \\
\text { Specialising with } \\
\text { geographical groups } \\
\text { Evidence base of what we do } \\
\text { Influence local clinical } \\
\text { governance }\end{array}$ & $\begin{array}{l}\text { Focusing on 'Excellence in } \\
\text { Sheffield' } \\
\text { Driving developments more } \\
\text { ourselves } \\
\text { Focused on core activity } \\
\text { Better inter-agency cooperation }\end{array}$ & $\begin{array}{l}\text { Expansion; new developments; } \\
\text { innovations } \\
\text { Research; training; supervision } \\
\text { Inter-agency cooperation } \\
\text { (psychology, other trusts) } \\
\text { Widening range of approaches } \\
\text { (Health Action Zones) } \\
\text { Link with wider teams } \\
\text { Links with universities }\end{array}$ \\
\hline$T$ & $\begin{array}{l}\text { 'Picking' certain approaches } \\
\text { Low priority } \\
\text { High cost of trained therapists } \\
\text { GP counselling established } \\
\text { Loss of 'specialist practice' }\end{array}$ & $\begin{array}{l}\text { Loss of income } \\
\text { Other agencies/teams bidding } \\
\text { for work } \\
\text { Regional services taking over } \\
\text { Problems with morale following } \\
\text { reduced staffing }\end{array}$ & $\begin{array}{l}\text { Other (cheaper) agencies/services } \\
\text { Costs of trained staff } \\
\text { Lack of priority in this area/ } \\
\text { contracting } \\
\text { Waiting lists - dumping of difficult } \\
\text { patients }\end{array}$ \\
\hline
\end{tabular}

GP, general practitioner.

our regional role were considered to be the most appropriate responses. This would ensure maintenance and development of a full range of highquality services accessible to the wider population.

The process highlighted the issues for this group of staff, who considered their own position in relation to the wider issues raised by the Government White Paper. Reviewing these issues and the process of the debate suggests a number of recommendations to consider when debating the future of small, specialised services.

\section{Recommendations}

Services should be commissioned and organised so that there are sufficient staff to form teams and to enable teams with different specialist skills to relate to each other.

There should be a system that enables the service to be accessible and responsive to local needs, involving all relevant parties in developing service agreements and implementing local or national service frameworks. These agreements should recognise the full range of functions of a specialist service and the importance of the support of colleagues in order to work as a specialist.

Professional accountability should be assured by developing a single framework for professional practice, training, supervision, guidelines and protocols informed by research and audit.

Irrespective of the many health care agendas, specialist therapists are expensive and scarce. It 
is therefore imperative that their skills and expertise are utilised effectively and efficiently to provide equitable services to meet patients needs.

\section{Acknowledgements}

Thanks to Peter Burtoft who facilitated the discussion and to all the staff in the Specialist Psychotherapy Directorate who contributed enthusiastically to the discussions.

\section{References}

DEPARTMENT OF HEALTH (1998) Our Healthier Nation: a Contract for Health. London: HMSO.

GARELCK, G. (1998) Reflections on purchasing psychotherapy services: the importance of unconscious factors. Psychoanalytic Psychotherapy, 12. 99-102.

Grant, S., Margison, F. \& POWELl. A. (1991) The future of psychotherapy services. Psychiatric Bulletin. 15. 174-179.

Grant, S., Holmes, J. \& WaTson, J. (1993) Guidelines for psychotherapy training as part of general professional training. Psychiatric Bulletin, 17, 695-698.

HoLmes, J. (1994) Psychotherapy - a luxury the NHS cannot afford? British Medical Journal, 309. 1070-1072.
- \& Mrtchison. S. (1995) A model for an integrated psychotherapy service. Psychiatric Bulletin. 19. 209-213.

NHS EXEcuTtve (1997) The New NHS-Modern. Dependenable. London: HMSO.

- (1998a) A First Class Service: Quality in the New NHS. London: HMSO.

- (1998b) Consultation on Commissioning Specialised Services. London: HMSO.

- (1998c) Draft Guidance on Out of Area Treatment. London: HMSO.

PARRY, G. \& RichaRdSON, A. (1996) NHS Psychotherapy Services in England: Review of Strategic Policy. London: MHSE-Department of Health.

PSyChotherAPY SPECIAUST SEction OF THE Royal College of PSYCHIATRISTS (1992) The profession of adult psychotherapist in the NHS. Psychiatric Bulletin, 16. 116-119.

Roth, A. D. \& Fonagy, P. (1996) What Works for Whom? A Critical Review of Psychotherapy Research. New York: Guilford Press.

TEMPLE. N. (1998) Notes on the psychotherapy review. Psychoanalytic Psychotherapy, 12. 99-102.

WHYTE, C. R. (1989) Staffing a district psychotherapy service. Psychiatric Bulletin. 13. 596-598.

Raymond Haddock, Consultant Psychotherapist, Director of Psychotherapy Services, Community Health Sheffield NHS Trust Specialist Psychotherapy Services, Brunswick House, 299 Glossop Road. Sheffield S10 2HL

\section{Getting the Message Across}

A review of research and theory about disseminating information in the NHS Claire Palmer and Julie Fenner

An essential requirement of effective clinical practice is the rapid dissemination

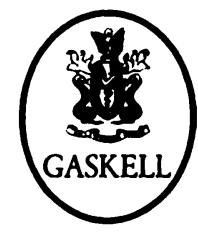
of research findings and their incorporation into practice. The usual dissemination method for NHS-generated research is publication in a professional journal and presentation at conferences. Occasionally educational strategies might be applied. There is increasing evidence that these strategies are often ineffective and that much of this new information is not adopted into practice for many years, if at all.

This book is aimed at all those in the long chain between the source of new information in the NHS (be it policy, research or managerial innovations) and its intended target audience. The book includes overviews of relevant research and theory to support the development of more effective dissemination strategies in the NHS.

June 1999, Paperback, ISBN 190124236 6, £10.00

Available from Book Sales, Royal College of Psychiatrists, 17 Belgrave Square, London SWIX 8PG Tel +44 (0) 1712352351 (extension 146) $9.30 \mathrm{am}-2$ pm, Fax +44 (0) 1712451231 http://muw.rcpsych.oc.uk 